\title{
A rare immature teratoma of the tela chorioidea of the third ventricle: late-onset, intrapartum ultrasound diagnosis and postnatal outcome
}

\author{
Gabriele Tonni • Gianpaolo Grisolia • Michela Nanni • \\ Arianna De Martino • Paolo Villani • Paolo Zampriolo
}

Received: 6 May 2014 / Accepted: 23 May 2014 / Published online: 6 June 2014

(C) Springer-Verlag Berlin Heidelberg 2014

\begin{abstract}
We describe a previously unreported case of immature teratoma originating from the tela chorioidea of the third ventricle diagnosed during labor at term of pregnancy. Postnatal MR imaging and pediatric neurosurgery with postnatal outcome at 6 months of age are reported.
\end{abstract}

Keywords Immature intracranial teratoma $\cdot$ Hydrocephalus · Prenatal ultrasound diagnosis - Magnetic resonance imaging · Pediatric neurosurgery $\cdot$ Histology

\section{Introduction}

Congenital intracranial tumors are rare diseases comprising $0.4-3.1 \%$ of all intracranial tumors, with teratomas representing $9-30 \%$ of them [1]. Most teratomas are midline tumors located predominantly in the sellar and pineal regions [1] and are usually incidentally diagnosed during routine second or third trimester scan with very rare early diagnosis [1-6]. The tumor usually replaces the intracranial contents and cause distortion of normal cerebral anatomy being represented by a solid/cystic mass lesion associated to hydrocephalus. Teratomas involve at least one type of tissue from each of the three embryonic layers (usually accompanied by solid

G. Tonni $(\bowtie)$

Prenatal Diagnostic Service, Department of Obstetrics and Gynecology, Guastalla Civil Hospital, AUSL Reggio Emilia, Via Amendola 1, Reggio Emilia, Italy

e-mail: tonnig@ausl.re.it

G. Grisolia $\cdot$ M. Nanni $\cdot$ P. Zampriolo

Prenatal Diagnostic Service, Department of Obstetrics and

Gynecology, "Carlo Poma” Hospital, Mantua, Italy

A. De Martino $\cdot$ P. Villani

Neonatal Intensive Care Unit, "Carlo Poma” Hospital, Mantua, Italy areas) and are most often of benign origin, although Thurkow et al. [7] has reported an extremely rare case of malignant teratoma of the neck, with mature and immature metastatic lesions in the lungs, in an immature fetus. Teratomas of the head and neck account for only $6 \%$ of all teratomas [8], with the majority involving the sacrococcygeal region in the fetus and the newborn [9]. Teratomas are composed of a variable admixture of skin, skin appendages, smooth muscle, cartilage, and respiratory and gastrointestinal epithelium [8]; embryonic tissue may be also present (in an "immature" teratoma) and is neural in type, as it often resembles a retinal anlage [9]. Due to the rapid growth of the tumor, the prognosis of teratomas is usually poor with a mortality rate around $90 \%[10,11]$.

We describe a previously unreported case of immature teratoma originating from the tela chorioidea of the third ventricle diagnosed during labor at term of pregnancy.

\section{Case report}

A 27-year-old with previous Cesarean section, underwent routine third trimester ultrasound examination at 31 weeks and 0 day of gestation. The scan was carried out using a realtime high-frequency ultrasound machine (Voluson E8, GE, Milwaukee, WI, USA) equipped with a 2D/3D transabdominal RAB 4-8D MHz probe. The fetus was in breech position and showed a normal growth with an estimated fetal weight of $1,969 \mathrm{~g}$. Amniotic fluid was normal. As the woman requested a trial of labor, a follow up scan performed at 37 weeks and 6 days of gestation showed cephalic presentation and normal biophysical profile score. The woman went into spontaneous labor at 40 weeks and 0 day of gestation. A scan performed at hospital admission incidentally revealed an intracranial mass, partly solid and cystic, located mainly at the level of the midline echo and causing severe obstructing hydrocephalus and secondary macrocephaly. These findings 
Fig. 1 Transabdominal intrapartum scan showing a partly solid, cystic, non-homogeneous tumor starting from cerebral midline echo at the level of the midbrain (third ventricle) (a) and filling the right lateral ventricle (b). Also, note the presence of an obstructive hydrocephalus

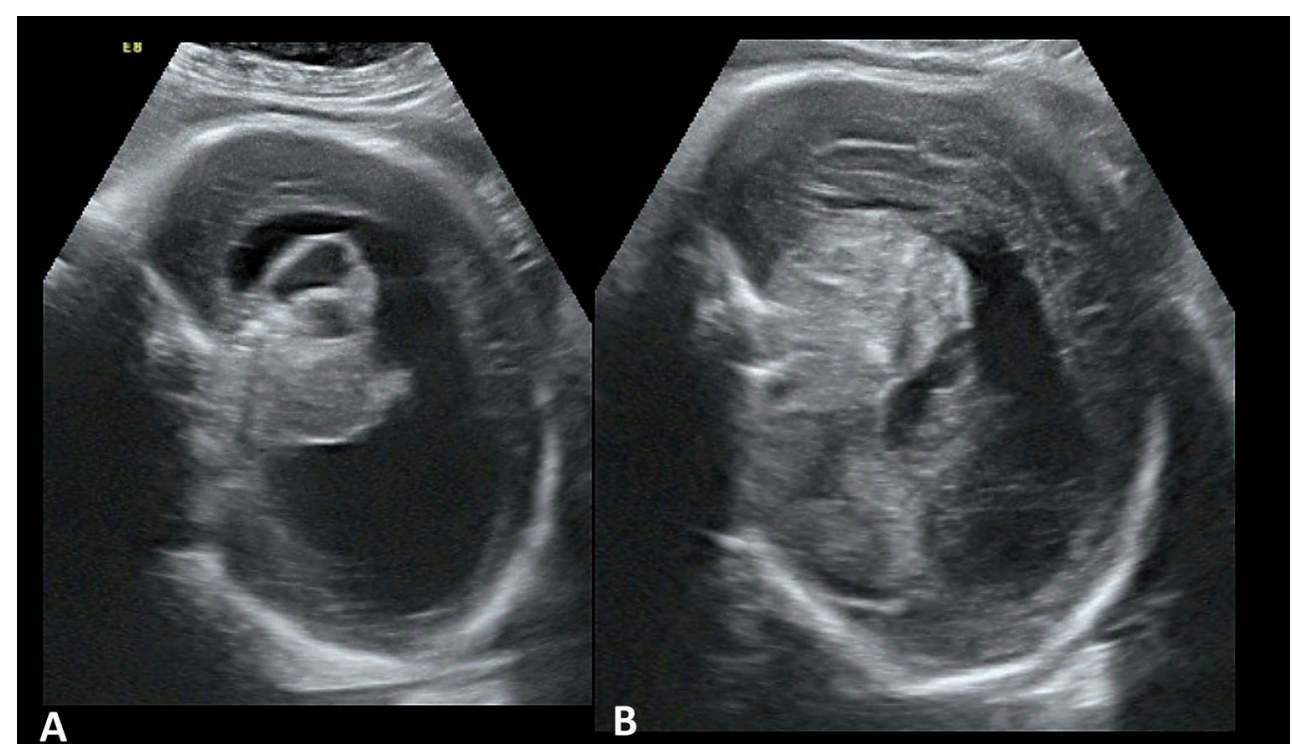

elicited a dedicated fetal neurosonogram that was conducted using the 2D/3D transabdominal and transvaginal approach. The neurosonogram demonstrated an increased biparietal diameter (BPD) $(107 \mathrm{~mm},>95$ th percentile for gestational age) and head circumference (HC) $(311 \mathrm{~mm},>95$ th percentile for gestational age), respectively. The midbrain (third

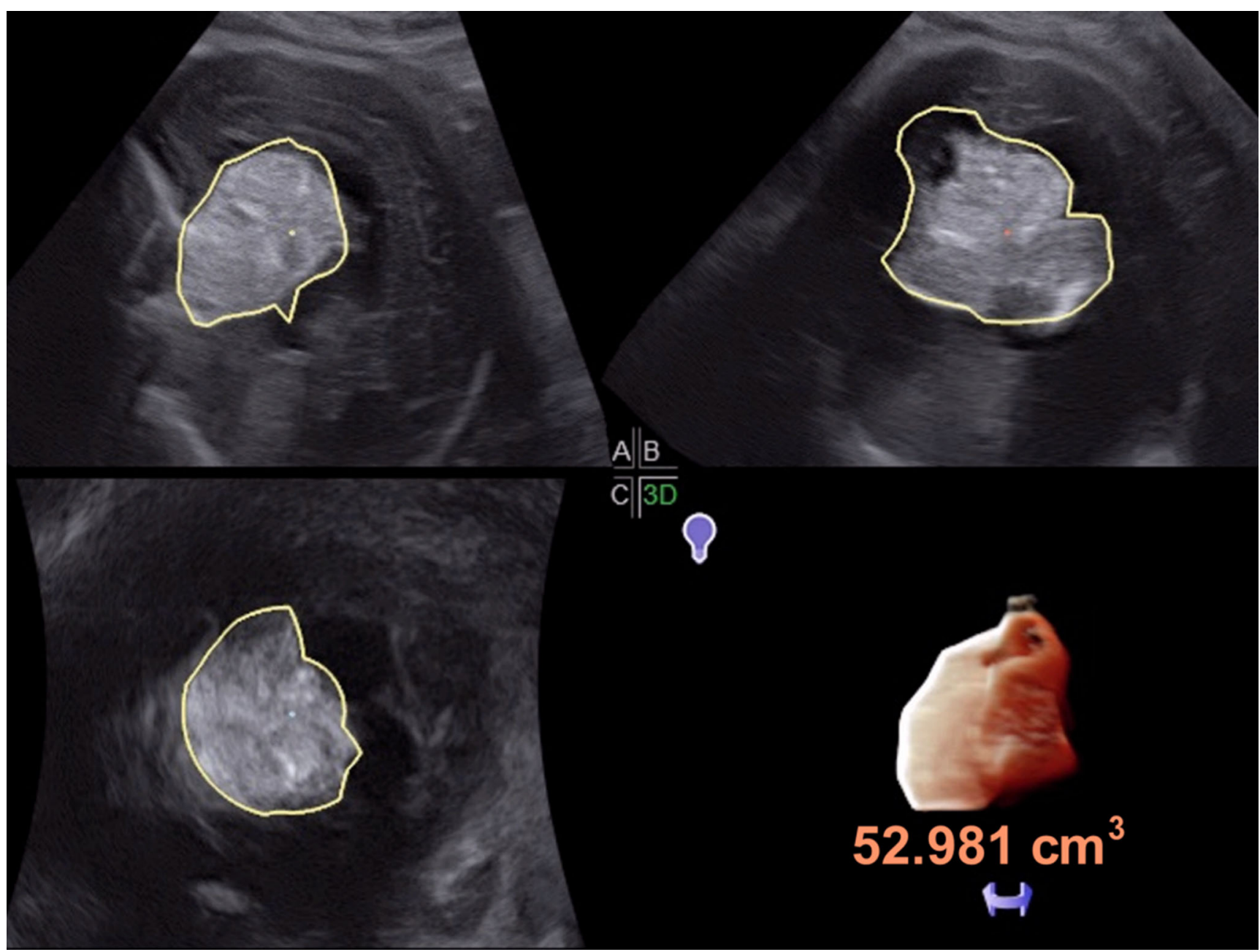

Fig. 2 Three-dimensional ultrasound: the volume of the tumor $\left(52.981 \mathrm{~cm}^{3}\right)$ was calculated using the VOCAL application 


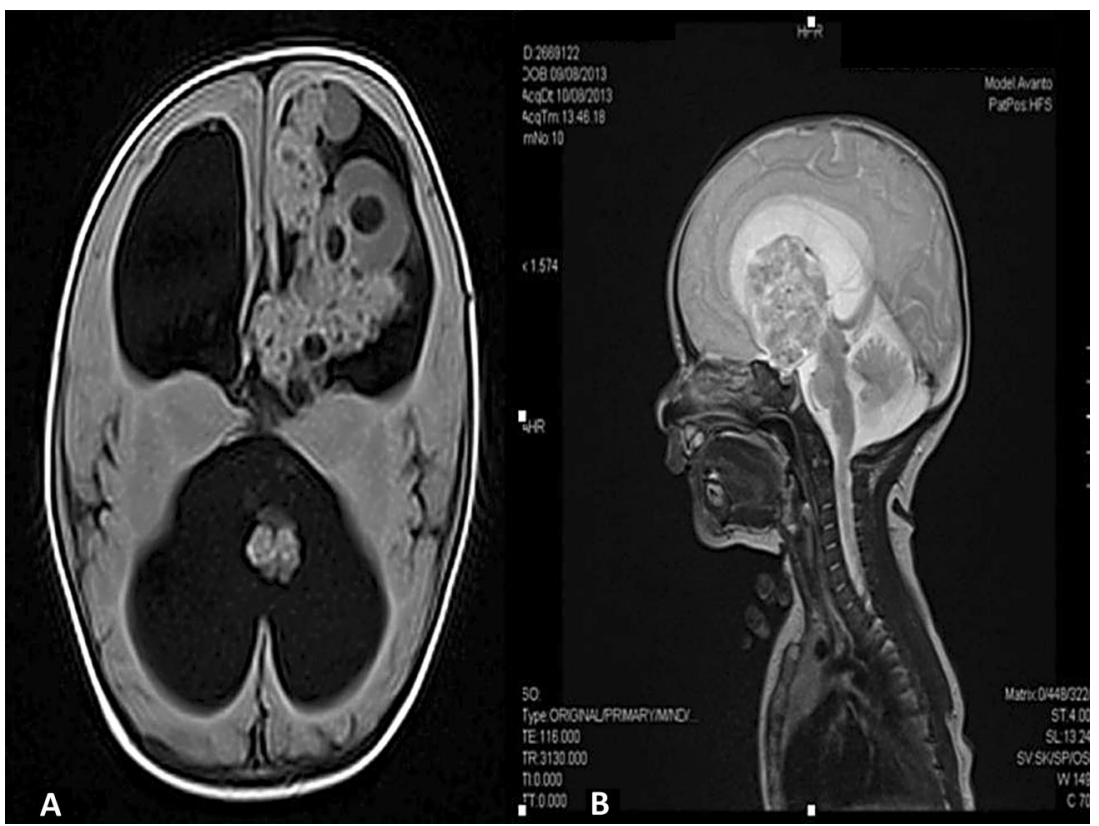

Fig. 3 a T2-weighted MR imaging performed at 1 day postnatal in the axial plane. Note that the tumor arises from the midbrain (third ventricle) and extends into the right lateral ventricle. Severe obstructing communicating hydrocephalus is confirmed. b Sagittal plane: the tumor extends caudally to reach the ethmoid-sphenoidal planum and the sellar diaphragm. The posterior-inferior portion reaches the interpeduncular

ventricle) was occupied by a large heterogeneous mass with solid and cystic content (Fig. 1), and volume calculated using VOCAL application was $52.981 \mathrm{~cm}^{3}$ (Fig. 2). Severe bilateral obstructed hydrocephalus was also observed. To prevent cephalopelvic disproportion, an intrapartum Cesarean section was performed following multispecialist counseling. A living female infant weighing 3,175 $\mathrm{g}$ was delivered. The 1- and 5min Apgar score were 8 and 9, respectively. The umbilical $\mathrm{pH}$ was 7.23 , and base excess was $-4 \mathrm{MEq} / \mathrm{L}$. The clinical examination of the newborn showed bulging and enlarged anterior fontanelle with sutures widely separated and a head circumference of $37.5 \mathrm{~cm}$ ( $>97$ th percentile). The eyes, ears, and neck were unremarkable. The brain ultrasound showed a large midbrain mass with hyperechogenic and hypoechogenic features measuring $37 \times 33 \mathrm{~mm}$. Angiographic study using color Doppler ultrasound revealed a forward flow pattern within the lesion. A communicating (bi-triventricular) obstructed hydrocephalus was confirmed. MR imaging was planned at day 1 postnatal life using a 1.5-T equipment (Intera Achieva ${ }^{\circledR}$, Philips Eindhoven, The Netherlands) with a sense body coil. T2-weighted images were acquired in the three orthogonal planes using a single-shot fast spin-echo (SSFSE) sequence with a repetition time of $15,000 \mathrm{~ms}$; echo time $120 \mathrm{~ms}$; echo train length 140 ; acquisitions 2 ; matrix $139 \times 256$ ). Each pulse sequence lasted $30 \mathrm{~s}$. T1- and T2-weighted imaging disclosed a large dishomogeneous tumor $(4.4 \times 3.9 \times 3.3 \mathrm{~cm})$, partly solid and cystic, filling the third ventricle and extending into the right lateral ventricle. Superiorly, the tumor involved the third cistern, with resulting splaying of the cerebral peduncles. A cystic component of the lesion extends behind the sella turcica abutting the hindbrain cistern. Superiorly, the tumor involves the third ventricle and the Monro foramina, thus causing ventricular dilatation. The pituitary pedicle and the optic chiasma are not detectable

ventricle and the Monro foramina; caudally, the tumor extended until the sellar diaphragm. Severe hydrocephalus involving the third and the fourth ventricle was confirmed (Fig. 3). The newborn infants was transferred to a tertiary neurosurgery care center at 3 days of life and underwent a ventriculoperitoneal shunt placement at day 7. Radical excision of the tumor was uneventfully carried out a week later. Histology examination revealed the intracranial mass to be an immature teratoma originating from the tela chorioidea of the third ventricle (Fig. 4).

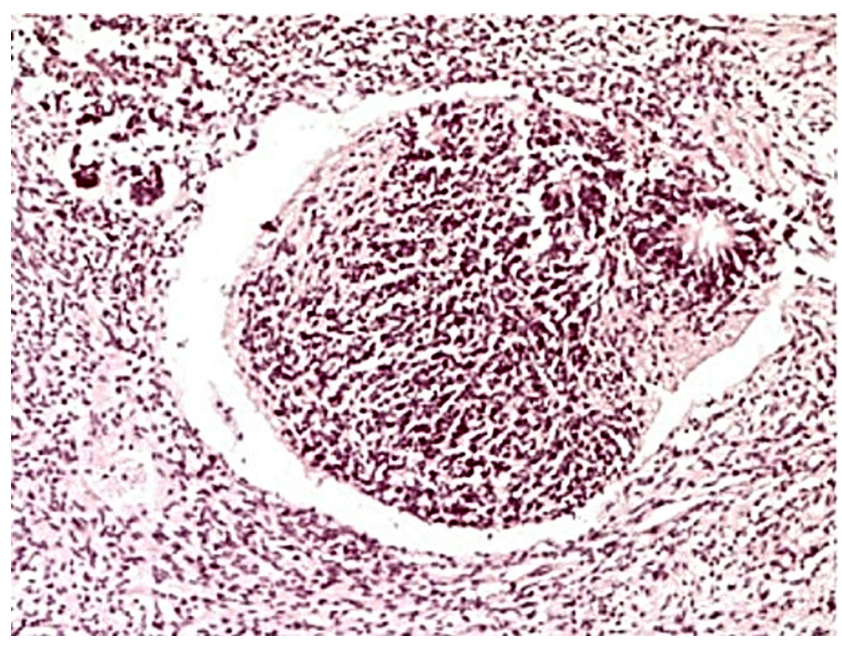

Fig. 4 Histological examination demonstrating an immature teratoma: the dominant tissue type in this tumor results from immature neuroepithelium in a fibrillary background (hematoxylin eosin $910 \mathrm{HPE}$ ) 
At 6 months of postnatal life, the infant is currently undergoing chemotherapy and anticonvulsant therapy and the neurodevelopmental outcome appears normal.

\section{Conclusion}

Teratomas are rare tumors composed of tissue originating in all three embryonic layers, with an occurrence of 1:20,000 to $1: 40,000$. Only $5 \%$ occur in the head or neck, and of these, malignant transformation has been reported in less than $5 \%$ of cases. Although the first case of intracranial teratoma has been reported in the 1864 [12], only a few cases of congenital intracranial teratomas have been described: massive tumors replacing the intracranial contents, smaller ones causing hydrocephalus, intracranial teratomas with extension into the orbit or neck, and teratomas presenting as an incidental postmortem finding in a stillborn fetus [10]. The knowledge of the anatomy of the third ventricle is essential to understand the clinical implication of an etheroplastic-growing mass located at its level and secondary complications like obstructing hydrocephalus and intraventricular hemorrhage. Nowadays, the prenatal diagnosis of intracranial tumors relies on ultrasound and antenatal/postnatal MR imaging or computed tomography (CT) scan. As of 2003, only two cases of congenital intracranial teratoma (CIT) have been reported by means of halfFourier single-shot turbo spin-echo (FASTE) imaging. Marden et al. [13] described the first case of CIT using the true fast imaging in steady-state procession (FISP) MR sequence. According to Marden et al. [13], true FISP can be obtained in almost $20 \mathrm{~s}$ and provides superior contrast resolution compared with HASTE. Prenatal detection is crucial for timely counseling to the parents and to arrange appropriate obstetric management and neonatal assistance. To potentially prevent cephalopelvic disproportion, Cesarean section is performed in $60 \%$ of cases [14]. Subdural hemorrhage [15] and fetus-in-fetu (FIF) [16] should be considered in the differential diagnosis of all congenital intracranial masses detected prenatally by ultrasound. Subdural hemorrhage is usually located in the supratentorial region, and maternal anticoagulant therapy, maternal abdominal trauma, and/or fetal coagulation disorders may be associated [17]. Fetus-in-fetu (FIF) is a rare condition where a degenerated fetiform mass is incorporated within the body of a fetus. Although most cases of fetus-in-fetu occur in the abdomen, Marnet et al. [16] reported a case of FIF of the third ventricle associated with a triventricular hydrocephalus resembling an intracranial teratoma.

Hydrocephalus may be the consequence of a hemorrhage caused by the tumor or by blockage of the ventricular draining system as it was in the current case. The prognosis of congenital intracranial teratomas is usually poor with only a $10 \%$ survival rate $[5,14,18,19]$.
To the best of our knowledge and after electronic search of PubMed/Medline using "intracranial tumor," "intracranial teratoma," and "congenital brain teratoma" as keywords, this is the first observation to report the prenatal diagnosis of a lateonset congenital intracranial teratoma. Postnatal MR imaging and neurosurgery with histologic examination confirmed this lesion to be an immature teratoma originating from the tela chorioidea of the third ventricle.

\section{References}

1. Arsian E, Usul H, Baykal S, Acar E, Eyuboglu EE, Reis A (2007) Massive congenital intracranial immature teratoma of the lateral ventricle with retro-orbital extension: a case report and review of the literature. Pediatr Neurosurg 43:338-342

2. Horton D, Pilling DW (1997) Early antenatal ultrasound diagnosis of fetal intracranial teratoma. Br J Radiol 70:1299-1301

3. Mazouni C, Porcu-Buisson G, Girard N, Sakr R, Figarella-Ballanger D, Guidicelli B, Bonnier P, Gamerre M (2003) Intrauterine brain teratoma: a case report of imaging (US, MRI) with neuropathologic correlations. Prenat Diagn 23:104-107

4. Muhonen MG, Bierman JS, Hussain NS, Hanley HA, Hussain SS (2005) Giant intracranial teratoma and lack of cortical development in a fetus. Case report. J Neurosurg 103(Suppl):180-183

5. Woodward PJ, Sohaey R, Kennedy A, Koeller KK (2005) From the archives of the AFIP: a comprehensive review of fetal tumors with pathologic correlation. Radiographics 25: $215-242$

6. Rickert CH, Probst-Cousin S, Louwen F, Feldt B, Gullotta F (1997) Congenital immature teratoma of the fetal brain. Childs Nerv Syst 13: $556-559$

7. Thurkow AL, Visser GH, Oosterhuis JW, de Vries JA (1982) Ultrasound observations of a malignant cervical teratoma of the fetus in a case of polyhydramnios: case history and review. Eur J Obstet Gynecol Reprod Biol 14:375-380

8. World Health Organization Classification of Tumors. Pathology and genetics of head and neck tumors (2005) In: Barnes L, Eveson JW, Reichart P, Sidransky D (eds) IARC Press, Lyon.

9. Pediatric Pathology (1981) In: Berry CL (Ed), Springer-Verlag, Berlin-Heidelberg- New York.

10. Isaacs H Jr (2002) Perinatal brain tumors: a review of 250 cases. Pediatr Neurol 27:249-261

11. Im SH, Wang KC, Kim SK, Lee YH, Chi JG, Cho BK (2003) Congenital intracranial teratoma: prenatal diagnosis and postnatal successful resection. Med Pediatr Oncol 40:57-61

12. Washburne JF, Magann EF, Chaukan SP (1995) Massive congenital intracranial teratoma with skull rupture at delivery. Am J Obstet Gynecol 173:226-228

13. Marden FA, Wippoid FJ 2nd, Perry A (2003) Fast magnetic resonance imaging in steady-state procession (true-FISP) in the prenatal diagnosis of a congenital brain teratoma. J Comput Assist Tomogr $27: 427-430$

14. Schlembach D, Bornemann A, Rupprecht T, Beinder E (1999) Fetal intracranial tumors detected by ultrasound: a report of two cases and review of the literature. Ultrasound Obstet Gynecol 14:407-418

15. Meagher SE, Walker SP, Choong S (2002) Mid-trimester fetal subdural hemorrhage: prenatal diagnosis. Ultrasound Obstet Gynecol 20: 296-298

16. Marnet D, Vinchon M, Kerdraon O, Joriot S, Chafiotte C, Dhellemmes P (2008) Antenatal diagnosis of a third 
ventricular mass: fetus in fetu or teratoma. Childs Nerv Syst 24:887-891

17. Saada J, Enza-Razavi F, Delahaye S, Martinovic J, Macaleese J, Benachi A (2009) Early second-trimester diagnosis of intracranial teratoma. Ultrasound Obstet Gynecol 33:109-111
18. Pinto V, Meo F, Loiudice L, D’Addario V (1999) Prenatal sonographic imaging of an immature intracranial teratoma. Fetal Diagn Ther 14:220-222

19. Chien YH, Tsao PN, Lee WT, Peng SF, Yau KI (2000) Congenital intracranial teratoma. Pediatr Neurol 22:72-74 